\title{
O PARADIGMA DA NUCLEARIZAÇÃO FRENTE À ESTABILIDADE REGIONAL: UMA ANÁLISE COMPARADA ENTRE COREIA DO NORTE E IRÃ SOB A LUZ DA DISSUASÃO
}

\author{
Jaine Garcia de Soura ${ }^{1}$ \\ Marianna de Oliveira Rodrigues ${ }^{2}$ \\ Pedro Henrique Silva de Oliveira ${ }^{3}$
}

\begin{abstract}
Resumo
Este artigo investiga a importância do programa nuclear do Irã para a garantia da estabilidade regional do Oriente Médio, a partir da análise comparada com o exitoso programa nuclear da Coreia do Norte. Desse modo, esta pesquisa trabalha com o método histórico comparativo. Nesse sentido, os autores trabalham com a hipótese de que a nuclearização do Estado iraniano traria um novo cenário de estabilidade do Complexo Regional de Segurança (CRS). Os resultados preliminares apontam para a necessidade de contrabalanço do protagonismo israelense em termos militares e nucleares regionais, conferindo à nuclearização iraniana o poder de atenuar assimetrias de poder entre os Estados, que são as responsáveis pela perpetuação dos conflitos. Sendo assim, a presente investigação parte de uma matriz teórica pautada na teoria da dissuasão e compreende que armamentos atômicos se constituem como elementos dissuasórios por excelência devido às suas capacidades de alterar as dinâmicas da balança de poder regional.
\end{abstract}

Palavras-chave: Dissuasão Nuclear. Irã. Coreia do Norte. Segurança Internacional.

\begin{abstract}
This paper investigates the importance of Iran's nuclear program for ensuring regional stability in the Middle East, based on a comparative analysis with North Korea's successful nuclear program. As such, the present research is guided by the comparative historical method. In the present investigation, the authors work with the hypothesis that the nuclearization of the iranian State would bring forth a new scenery of stability of the middle-eastern Regional Security Complex (RCS). The results support the idea of counterbalance to the ever-growing nuclear and military israelian presence, due to that, the nuclearization of Iran can attenuate the power asymmetries between States, which are responsible for the perpetuation of conflicts in the region. Thus, this research is guided by the theoretical matrix in deterrence theory and understands that nuclear weapons are constituted as a deterrent element par excellence due to its ability to change the dynamics of regional power balance.
\end{abstract}

Keywords: Nuclear Deterrence. Iran. North Korea. International Security.

\footnotetext{
${ }^{1}$ Mestranda em Estudos Estratégicos Internacionais pela Universidade Federal do Rio Grande do Sul (PPGEEIUFRGS). Bacharela em Relações Internacionais pelo Centro Universitário Ritter dos Reis (UniRitter). Monitora de Pesquisa Acadêmica no Laboratório de Estudos em Defesa e Segurança (LEDS-UniRitter). Pesquisadora associada ao Instituto Sul-Americano de Política e Estratégia (ISAPE), e ao Núcleo de Estudos Estratégicos, Geopolítica de Integração Regional (NEEGI-UNILA). Contato: jaine.gsouza95@gmail.com. Orcid: https://orcid.org/0000-0001-6625-2313

${ }^{2}$ Professora da Escola Superior de Relações Exteriores (ESRI). Editora da Revista Relações Exteriores. Mestra em Estudos Estratégicos Internacionais pela Universidade Federal do Rio Grande do Sul (PPGEEI-UFRGS). Bacharela em Relações Internacionais pelo Centro Universitário Ritter dos Reis (UniRitter). Pesquisadora associada ao Instituto Sul-Americano de Política e Estratégia (ISAPE), ao Núcleo de Estudos Estratégicos, Geopolítica de Integração Regional (NEEGI-UNILA) e ao Laboratório de Estudos em Defesa e Segurança (LEDSUniRitter). Contato: marianna.oliveira08@ gmail.com. Orcid: https://orcid.org/0000-0002-4282-410X

${ }^{3}$ Doutorando em Ciência Política pela Universidade Federal do Rio Grande do Sul (UFRGS). Mestre em Ciência Política pela Universidade Federal de Pelotas (PPGCPol - UFPel). Bacharel em Relações Internacionais pela Universidade Federal de Pelotas (UFPel). Pesquisador junto ao Grupo de Pesquisa em Política Internacional e Gestão Oceânica, Estudos Marítimos e Ciências do Mar, Configurações e tensionamento das dinâmicas do crime e das ações coletivas no Brasil contemporâneas. Contato: pedrohsdeoliveira27@gmail.com Orcid: https://orcid.org/0000-0002-9179-1842
} 


\section{Resumen}

Ese artículo se dedica a la investigación de la importancia del programa nuclear de Irán para garantizar la estabilidad regional del Medio Oriente, basado en una análisis comparada con el exitoso programa nuclear de Corea del Norte. Haciendo uso del método de historia comparada, se construye la hipótesis que la nuclearización del Estado iraní podría crear un nuevo escenario de estabilidad en el Complejo Regional de Seguridad (CRS). Los resultados indican la necesidad de contrarrestar el liderazgo de Israel en temas militares y nucleares en la región, dando a la nuclearización iraní el poder de atenuar las asimetrías entre los Estados, que hoy se presentan como las responsables de la continuidad de los conflictos. Así, esta investigación se guía por la matriz teórica en la teoría de la disuasión y entiende que las armas nucleares se constituyen como un elemento disuasorio por excelencia por su capacidad para cambiar la dinámica del equilibrio de poder regional.

Palabras claves: Disuasión Nuclear. Irán. Corea del Norte. Seguridad Internacional.

\section{INTRODUÇÃO}

Este artigo busca investigar o papel do programa nuclear iraniano na garantia da estabilidade regional do Oriente Médio. Tal pretensão vem a partir das ideias de Kenneth Waltz (2012) no artigo “Why Iran Should Get the Bomb: Nuclear Balancing Would Mean Stability”, em que afirma que nenhuma solução para a crise no Oriente Médio seria viável sem a restauração da balança de poder militar. Diante disso, a estabilização regional estaria ligada à aquisição de armas nucleares por parte do Irã. A arguição de Waltz, sobre o caráter dissuasório de armamentos nucleares, encontra ressonância na postura adotada pela Coreia do Norte em relação ao seu arsenal atômico. Pyongyang apresenta pragmatismo quanto às pressões de potências nucleares maiores como Estados Unidos (EUA) e o Reino Unido (UK), não deixando de lado seu programa nuclear como fizeram Iraque, Líbia e Síria, por exemplo.

Assim, norteando-se pelo êxito da postura norte-coreana, este artigo investiga as lições que o êxito deste modelo podem ensinar ao programa iraniano. Para isto, por meio da revisão bibliográfica de fontes secundárias, realiza-se uma análise comparativa entre as duas potências nucleares regionais. A busca por similaridades e diferenças se dá através de eixos que contemplam as condições, conjunturas, cenários e implicações dos objetos aqui analisados e de seus respectivos entornos regionais. Assim, busca-se identificar a emergência de um novo padrão de comportamento entre potências nucleares emergentes - passível de alterar não somente a balança de poder internacional, como também as dinâmicas da segurança -, trabalhando com a hipótese de que a nuclearização do Estado iraniano traria um novo cenário de estabilidade do Complexo Regional de Segurança (CRS) ${ }^{4}$ para o Oriente Médio.

\footnotetext{
${ }^{4}$ O conceito de Complexo Regional de Segurança surge a partir da definição de Barry Buzan e Ole Waever, em sua obra "Regions and Powers: the structure of International Security", publicada no ano de 2003. Se refere a territórios
} 


\section{A DISSUASÃO NUCLEAR: DA GUERRA FRIA À DISSUASÃO COMPLEXA}

Como ponto de partida, é necessária a introdução a respeito do conceito de dissuasão nuclear. Inicialmente, aponta-se a profundidade do debate existente no campo das Relações Internacionais (RI) para conceituar "dissuasão". Questões relativas à abrangência do termo, e à diferença entre "dissuasão" e "defesa" são apenas algumas das muitas que permeiam o debate (KNOPF, 2009; WALTZ, 1990).

Neste sentido, seguem-se as orientações de Knopf (2009) adotando a definição mais ampla do conceito de dissuasão, entendida como "uma forma de influência preventiva que se apoia principalmente em incentivos negativos" (KNOPF, 2009, p. 37, tradução nossa). O uso de tal conceituação permite uma leitura mais flexível da Teoria da Dissuasão, bem como, o emprego de seus conceitos para estudar objetos tradicionalmente não abarcados pela literatura especializada, como os rogue states ${ }^{5}$ e países que recém adquiriram a bomba atômica.

Diferentemente de uma estratégia de defesa, a dissuasão não objetiva afastar um invasor, mas tornar quaisquer atos de agressão custosos demais mesmo na condição de vitória. Assim, categoriza-se a dissuasão como uma forma de influência, atuando diretamente nos cálculos de custobenefício realizados ${ }^{6}$ pelos atores envolvidos nos processos de tomada de decisão (KNOPF, 2009; WALTZ, 1990). Assim, o efeito da dissuasão é mais psicológico do que físico ${ }^{7}$, usando de estímulos negativos diante de certas decisões, como coloca Waltz: "[a dissuasão] depende do que se pode fazer, não do que se farâ' (WALTZ, 1990, p. 733, grifo no original, tradução nossa).

Waltz (1990) aponta que as táticas de dissuasão são prévias ao uso de armamentos nucleares. Contudo, essas táticas eram empregadas sempre em consonância com estratégias de defesa. Segundo Stanley Baldwin (1930), um avião bombardeiro sempre iria passar despercebido pelas defesas e atingir seu alvo, portanto a própria existência de bombardeiros seria suficiente para

geograficamente próximos, que se interligam através de ameaças comuns às suas estruturas securitárias, ameaças essas que só podem ser dissolvidas por meio de soluções orquestradas de forma conjunta.

${ }^{5}$ Como uma categoria que não fora socialmente construída mas politicamente, existe uma certa dificuldade de precisar conceitualmente o que é um rogue state. Trata-se de um rótulo que é empregado tanto pelos Estados Unidos para se referir a regimes que ameaçam sua existência, quanto pela literatura especializada para designar Estados com características objetivas. Assim, o campo acadêmico trata tal conceito como uma categoria ampla, identificando quatro dimensões para categorizar um rogue state: "a imprevisibilidade, a violação das leis e normas internacionais, a hostilidade aos interesses americanos e a opressão doméstica” (JARVIS 2009, p. 142, tradução nossa).

${ }^{6}$ Ao fazer uso dessa categoria, a Teoria da Dissuasão parte de uma premissa sobre a existência de uma racionalidade instrumental por parte dos atores envolvidos, pressupondo que suas ações são ditadas por um cálculo de custo benefício.

${ }^{7}$ Knopf (2009), ao apresentar essa distinção se refere a clássica distinção elaborada por Thomas Schelling sobre força bruta e coerção. Onde estratégias de força bruta, buscam eliminar a possibilidade de escolha do adversário por meio do uso da dominação física. A dissuasão, no entanto, mantém a habilidade do outro escolher, mas busca coagir o adversário a tomar uma certa decisão por meio de ameaças. 
dissuadir confrontos. Todavia, com a Guerra Fria e o advento das armas nucleares, a dissuasão passou a assumir destaque como uma teoria per se, dado que:

As armas nucleares purificam estratégias de dissuasão, removendo elementos de defesa e combate. Ogivas nucleares eliminam a necessidade de lutar e eliminam a possibilidade de defesa, porque apenas um pequeno número de ogivas precisa atingir seus alvos (WALTZ, 1990, p. 732 , tradução e grifo dos autores).

A Guerra Fria teve o papel de demonstrar as consequências estratégicas de uma disputa hegemônica, protagonizada por dois atores com capacidades plenas de executar um second strike nuclear. Diferentemente da era pré-nuclear, onde as grandes potências travaram intensas guerras por seus interesses estratégicos, a Guerra Fria fora marcada pelo não engajamento militar direto entre as superpotências mundiais que a protagonizaram (KREPON, 2003; PAUL, 2009; WALTZ, 1990). No centro disso, encontrava-se a Teoria da Dissuasão Nuclear, que passou a ser considerada como "principal quadro teórico e político durante a Guerra Fria” (PAUL 2009, p. 1, tradução dos autores).

Originalmente formulada com base na "retaliação massiva", evoluiu a partir do governo de Eisenhower e do crescimento nuclear da União Soviética (URSS), assumindo a forma do Mutually Assured Destruction $(M A D)$. Seus paradigmas nortearam grande parte das políticas adotadas no mundo bipolar, portanto, mais do que uma teoria, a dissuasão é "uma tática, uma estratégia de segurança nacional, uma abordagem mais ampla da política de defesa" (PAUL, 2009, p. 5, tradução dos autores). Tradicionalmente, a Teoria da Dissuasão repousa sobre três premissas: “ii) para que a dissuasão seja bem-sucedida, um dissuasor deve ter capacidade suficiente; ii) sua ameaça deve ser credível; e iii) deve ser capaz de comunicar a ameaça ao seu oponente" (PAUL, 2009, p. 2, tradução nossa). Se na guerra é "imperativa a necessidade de não dar o primeiro passo sem considerar o último" (CLAUSEWITZ, 2007, p. 228, tradução dos autores), a nebulosidade resultante da $M A D$ era suficiente para intensificar o impasse entre os EUA e a URSS. Como resultado, ambos conseguiram evitar um confronto nuclear direto, disputando vantagens de diversas maneiras, incluindo Guerras de Proxy. Os teóricos das RI denominam tal situação como paradoxo da estabilidade-instabilidade. Contudo, a queda da URSS, e o subsequente fim da Guerra Fria, marcaram o início de um forte questionamento à Teoria da Dissuasão. Demonstrou ceticismo quanto às suas potencialidades analíticas durante a era das novas ameaças securitárias, como as nações recém nuclearizadas e os rogue states (PAYNE, 2003).

A Guerra de Cargil (1999) entre Índia e Paquistão é considerada emblemática frente às contrariedades da Teoria da Dissuasão no século XXI. Ambos os participantes disputaram conflito armado, apesar de serem potências nucleares plenamente capazes de realizar um second strike. 
Defensores da Teoria da Dissuasão pontuam que o temor de uma guerra nuclear seria impeditivo para o escalonamento das tensões regionais ao ponto de um conflito armado (ainda se enquadrando dentro do paradoxo da instabilidade-estabilidade). Contudo, a emergência de uma intensa crise militar entre potências atômicas demonstra que apenas a posse da bomba não é o bastante para prevenir uma crise (KREPON, 2003; PAUL, 2009). Eventos como este expuseram que a lógica da Guerra Fria não era mais aplicável ao SI moderno. Todavia, não foi o fim de seu poder explicativo, apenas emergiu a necessidade de sua adaptação à contemporaneidade, dando origem ao conceito de "Dissuasão Complexa" ${ }^{8}$. Devido ao objeto de análise das próximas seções, destaca-se como pertinente ao presente estudo as seguintes categorias: a dissuasão entre novos Estados nucleares, que assumiu maior proeminência no século XXI, e a literatura especializada encontra na Índia e no Paquistão um modelo a partir do qual preconiza a possibilidade de uma relação entre Irã-Israel e Japão-Coréia do Norte. Sua compreensão se divide em dois blocos: dos “pessimistas" que apontam como esta categoria desafia os três preceitos básicos da dissuasão, e dos "otimistas", que notam que apesar disso o exemplo tradicional é marcado pela não escalada de conflitos. No geral, devido a carência de mais casos, esta categoria configura-se como uma grande lacuna dentro dos estudiosos da dissuasão (KREPON, 2003; PAUL, 2009). Por fim, a dissuasão e dissuasão estendida envolvendo grandes potências nucleares e potências regionais armadas com armas químicas, biológicas e nucleares é uma categoria que não levantou muitos questionamentos durante a Guerra Fria, mas é digna de observação, encontrando na relação Israel-Mundo Árabe seu maior exemplo. A condição de Israel de potência nuclear não resultou no fim dos conflitos com o mundo árabe, o que aponta para duas conclusões: (i) as armas de destruição em massa não nucleares podem agir como dissuasor de conflitos nucleares; (ii) é inteiramente possível que um Estado mais fraco militarmente tenha êxito em dissuadir um com maior força militar.

\footnotetext{
${ }^{8}$ Os teóricos desse campo compreendem a miríade de relações possíveis e apresentam cinco tipos ideais de relações dissuasórias para nortear suas análises, sendo: 1. Dissuasão entre grandes potências, 2. Dissuasão entre novos estados nucleares, 3. Dissuasão e dissuasão estendida envolvendo grandes potências nucleares e potências regionais armadas com armas químicas, biológicas e nucleares, 4. Dissuasão entre estados nucleares e atores não estatais, 5 . Dissuasão por atores coletivos (PAUL, 2009, p. 9, tradução dos autores).

${ }_{9}$ Para uma leitura mais aprofundada, recomenda-se Krepon (2003).
} 


\section{O DESAFIO DA SEGUNDA ERA NUCLEAR: OS CASOS DA COREIA DO NORTE E DO IRÃ}

\subsection{COREIA DO NORTE E OS DESAFIOS REGIONAIS PARA O LESTE ASIÁTICO}

Desde sua fundação, em 1948, a política defensiva adotada pela República Popular Democrática da Coreia (DPRK $)^{10}$ visava o fortalecimento de seu poder militar e ofensivo na região, considerando que a situação securitária na península coreana "não se tornou menos dinâmica, e nem a ameaça militar no Extremo Oriente diminuiu como resultado da Guerra da Coreia (19501953) ${ }^{11}$ ou mesmo a Guerra Fria"12 (ROMASHKINA, 2007, p. 12). No decorrer de sua história, a estratégia nuclear norte-coreana é caracterizada por sua ambiguidade e imprevisibilidade, fator potencializado pela escassez de transparência sobre as intenções de Pyongyang (MCEACHERN \& MCEACHERN, 2018).

No início da década de 1950, no mesmo ritmo de outras nações do SI, Kim Il-Sung (19481994) iniciou a busca por armas nucleares - para contrapor aos EUA - buscando auxílio da URSS e da China (CLEMENS, 2010). O alinhamento de Pyongyang com o bloco comunista ofereceu conexões privilegiadas à concretização do desenvolvimento de um programa nuclear próprio, auxiliando no avanço das pesquisas relativas aos armamentos nucleares, à indústria atômica e à qualidade do minério de urânio. Contudo, destaca-se as relações assimétricas no campo militar, econômico e técnico-científico entre os atores, disparidades que, segundo Clemens (2010), contribuíram para o desgaste das propostas de cooperação entre a DPRK e a URSS na década de 1960. Em 1963, um ano após o primeiro teste nuclear chinês ${ }^{13}$, Pyongyang construiu um centro nuclear que contava com um reator de $5 \mathrm{MW}$ (megawatt), que entrou em operação no final da década

\footnotetext{
${ }^{10}$ Representa $55 \%$ da área total da península coreana, possui fronteiras ao norte e noroeste com a China e a Rússia, e ao sul pela Coreia do Sul (FRENCH, 2007).

${ }^{11}$ A guerra em si teve duração de três anos, até a assinatura do acordo de armistício, por conta da especificação de cessar as hostilidades até a concretização de uma solução pacífica, criou-se a DMZ (Zona Desmilitarizada da Coreia) próximo ao paralelo 38, isto significa que atualmente, após 67 anos desde a assinatura do armistício, a guerra da Coreia ainda não acabou. Ademais, a fronteira entre as Coreias é a mais militarizada do Sistema Internacional (STACK, 2018; FRENCH, 2007).

12 Tradução nossa do original: "has not become less dynamic nor did the military threat in the Far East diminish as a result of the Korean War (1950-1953) or the Cold War” (ROMASHKINA 2007, p. 12).

${ }^{13}$ A China, do mesmo modo que a Coreia do Norte, buscou auxílio com a URSS para uma aliança que contribuísse na criação e fortalecimento de seu programa nacional nuclear. Em 1959 as relações sino-soviéticas foram quebradas e com isso a assistência ao programa nuclear chinês. Como consequência, deu-se continuidade ao Projeto 596 (homenagem a data de independência, junho de 1959), e em outubro de 1964 foi conduzido com sucesso o teste da primeira bomba atômica chinesa ("dispositivo com implosão de urânio com 22 quilotons de força no topo de uma torre de aço de 100 metros"), tornando-se assim o quinto país a possuir armas nucleares (ATOMIC HERITAGE FOUNDATION, 2018).
} 
de 1960, com uso dual para reprocessamento de plutônio ${ }^{14}$ (ROMASHKINA, 2007). Inicialmente, a construção das instalações não levantou preocupações no SI, pois seu uso foi atribuído à esfera civil.

Em 1985, a Coreia do Norte assinou o TNP (Tratado de Não Proliferação). Visando minimizar a instabilidade regional da península, ambas Coreias assinaram a Declaração Conjunta de Desnuclearização da Península Coreana ${ }^{15}$, (UN, 1992a) e o Acordo de Reconciliação, Não Agressão e Intercâmbio e Cooperação entre o Sul e o Norte (UN, 1992b). Já com a chegada dos anos 1990, despontaram as iniciativas para um ambiente menos turbulento, trazendo a Política Sunshine, buscando a transformação gradual do regime norte-coreano em um parceiro na paz e prosperidade (CHO, 2016). Faz-se necessário apontar que, mesmo durante esse momento marcado pela tentativa de aproximação entre as Coréias, Pyongyang manteve sua posição relativa ao aprimoramento de suas capacidades nucleares, conforme os ditames da autossuficiência promulgada por sua ideologia, a Juche. Tais características fazem da Coreia do Norte um grande desafio para a comunidade internacional, situação agravada com sua saída do TNP, em 2003 (SAUER, 2006).

\subsubsection{AS CRISES NUCLEARES E AS CAPACIDADES NORTE-COREANAS}

O impacto da saída norte-coreana do TNP explicitou a inviabilidade da política Sunshine. Ademais, outro grande problema estava na ameaça que as forças militares convencionais, as WMD $^{16}$ e os mísseis balísticos trariam aos países da região e aos EUA (CHA \& KANG, 2003). Objetivando compreender as mudanças táticas no comportamento norte-coreano, é imperativo analisar as crises nucleares e os métodos utilizados para garantir o não escalonamento do dilema securitário $^{17}$, as crises estão representadas no quadro abaixo:

\footnotetext{
${ }^{14}$ Este reator ficou conhecido como o responsável pela maior parte do plutônio para as armas norte-coreanas (BBC, 2019).

15 Tinha por objetivo que ambas as partes: i) cessassem os testes, a produção, a manufatura, a posse, o recebimento, armazenamento, a implantação e o uso de armas nucleares; ii) a utilização de energia nuclear fosse meramente para propósitos pacíficos; iii) não possuíssem instalações de reprocessamento nuclear e enriquecimento de urânio (UN, 1992a).

${ }^{16}$ Weapons of Mass Destruction.

17 O Dilema de Segurança é um conceito criado por John Herz (1950), no qual a em uma estrutura internacional de natureza anárquica, onde os Estados são os únicos responsáveis pela garantia de sua própria segurança, sobrevivência e manutenção de sua soberania, a tendência aponta para um aumento cada vez maior por poder e capacidades militares a serem empregados em sua defesa. Contudo, nessa busca crescente, acabam por despertar a insegurança nos Estados de seu entorno, gerando nestes o ímpeto à busca por mais poderio bélico, sob a escusa da autodefesa, transformando o Sistema Internacional em um ambiente mais propenso à entropia e à eclosão de conflitos (HERZ, 1950).
} 
Quadro 01 - Histórico das crises nucleares

\begin{tabular}{|c|c|c|}
\hline Ano & Características & Implicações ao SI \\
\hline 1994 & $\begin{array}{c}\text { Intenção de se retirar do TNP; remoção das } \\
\text { peças do reator sem a supervisão dos inspetores } \\
\text { da AIEA (Agência Internacional de Energia } \\
\text { Atômica); }\end{array}$ & $\begin{array}{l}\text { A retirada dos inspetores da AIEA tornava } \\
\text { difícil reconstruir o histórico do reator; } \\
\text { criação do Agreed Framework (congelamento } \\
\text { das atividades nos reatores de gás-grafite } \\
\text { [DPRK] e construção de dois reatores de } \\
\text { energia de água leve + garantia contra a } \\
\text { ameaça ou uso de armas nucleares [EUA]); }\end{array}$ \\
\hline 2003 & $\begin{array}{c}\text { Início da construção da instalação para } \\
\text { enriquecimento de urânio; suspender o } \\
\text { congelamento das instalações nucleares; expulsar } \\
\text { os inspetores da AIEA; anunciar a retirada do } \\
\text { TNP; }\end{array}$ & $\begin{array}{l}\text { Revisão da Política norte-coreana feita pelos } \\
\text { estadunidenses que visava uma melhor } \\
\text { implementação do que fora acordado no } \\
\text { Agreed Framework; criação do Six-Party Talks } \\
\text { (Coreia do Norte, Coreia do Sul, Japão, } \\
\text { China, Rússia e EUA), que almejava a } \\
\text { resolução pacífica sobre o programa nuclear } \\
\text { da DPRK; }\end{array}$ \\
\hline $2006 / 2009$ & $\begin{array}{c}\text { Primeiro teste nuclear; envio da declaração } \\
\text { comprovando o desmantelamento das instalações } \\
\text { seis meses após o prazo; expulsão dos inspetores } \\
\text { da AIEA e dos EUA, dando início a } \\
\text { reconstrução do reator em Yongbyon; segundo } \\
\text { teste nuclear; decide não participar mais dos } \\
\text { encontros do Six-Party Talks e seguir os acordos } \\
\text { estabelecidos; }\end{array}$ & $\begin{array}{c}\text { Sanções econômicas aplicadas pelo CSNU } \\
\text { (resolução 1718, resolução 1874); outubro de } \\
2008 \text { a Coreia do Norte sai da lista } \\
\text { estadunidense de terrorismo; }\end{array}$ \\
\hline 2012 & $\begin{array}{l}\text { Lançamento do foguete Unha em abril e outro } \\
\text { em dezembro; }\end{array}$ & $\begin{array}{l}\text { O lançamento foi considerado violação do } \\
\text { acordo bilateral entre EUA/DPRK e o } \\
\text { auxílio alimentício fora retirado; sanções } \\
\text { expressas na resolução } 2087 \text { do CSNU; }\end{array}$ \\
\hline 2016 & \begin{tabular}{|} 
Quarto e quinto teste nuclear; teste de um \\
dispositivo termonuclear; reiniciou o \\
reprocessamento de barras de combustível usadas \\
no intuito de criar mais plutônio para seu \\
programa de armas nucleares;
\end{tabular} & $\begin{array}{l}\text { Sanções impostas à DPRK através das } \\
\text { resoluções } 2270 \text { e 2321; }\end{array}$ \\
\hline 2017 & $\begin{array}{l}\text { Sexto teste nuclear; teste do ICBM Hwasong- } \\
\qquad 14 \text { e do Hwasong-15; }\end{array}$ & $\begin{array}{l}\text { Relação entre EUA e DPRK deteriora devido } \\
\text { às provocações entre Trump e Kim; }\end{array}$ \\
\hline
\end{tabular}

Fonte: UN, 2006; UN, 2009; CBS, 2017; NTI, 2018 (adaptado pelos autores)

A crescente preocupação com a possível proliferação de armas nucleares - levando em conta os tratados e acordos firmados entre os países nucleares - não fora suficiente para diminuir as ambições nucleares de Pyongyang. Até o momento foram realizados 149 testes/lançamentos de mísseis, representados no gráfico 01 (NTI, 2020). Em um pronunciamento de 2017, Kim Jong-un 
afirma que o grande avanço de seu programa nuclear "[...] consolida a capacidade de defesa da Coreia Juche, e nosso país alcança o status de potência nuclear, um gigante militar no Oriente que

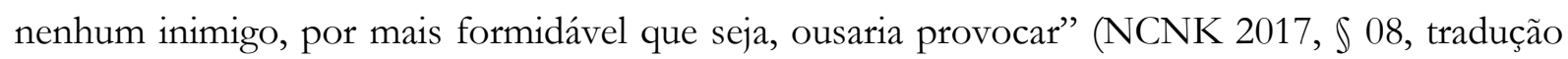
nossa).

Gráfico 01 - Histórico de lançamentos de mísseis Norte-Coreanos

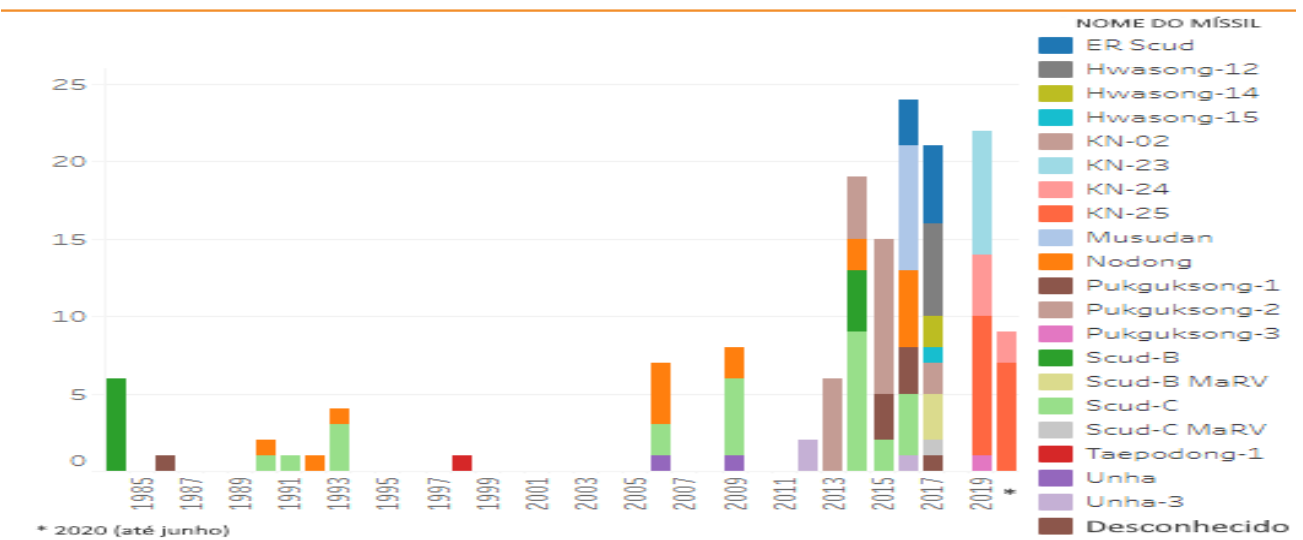

Fonte: NTI, 2020 (adaptado pelos autores)

O estudo do entendimento da família Kim sobre as armas nucleares, espalhadas por todo território nacional, enfatiza seu papel como garantidoras da sobrevivência de seu Estado, agindo como um equalizador estratégico frente às forças da ROK e dos EUA (LOWTHER \& DODGE, 2017). À vista disso, e da exposição das ambições norte-coreanas pela obtenção de armas nucleares, clarifica-se que sua postura ao longo das últimas décadas se deu em resposta ao crescente foco geopolítico dos EUA na Ásia, no qual Washington objetiva mitigar a ameaça nuclear de Pyongyang, bem como, o crescimento de Pequim (AKHTAR \& KHAN, 2014). A postura nuclear da Coreia do Norte trouxe três consequências ao Regime de Não-Proliferação: i) respostas regionais cada vez mais ofensivas; ii) impacto devastador no TNP; e iii) aumento da proliferação de materiais nucleares entre nações que buscam criar e/ou fortalecer seu arsenal de armas nucleares.

\subsection{O IRÃ NUCLEAR E AS ALTERAÇÕES NA ORDEM REGIONAL DO ORIENTE MÉDIO}

Iniciado na década de 1950, o programa nuclear da República Islâmica do Irã tem enfrentado várias nuances em seu desenvolvimento. Nascido de uma parceria do Irã do Xá Mohammed Reza 
Pahlavi com os EUA de Dwight Eisenhower, no programa Átomos pela Paz ${ }^{18}$, hoje é um dos principais focos da agenda dos EUA, colocando o Irã como seu principal adversário no Oriente Médio (PETERSON, 2011; GAIETTA, 2015; MORGADE, 2020).

Desde a Revolução Islâmica Iraniana, em 1979, as relações EUA-Irã se estremeceram, principalmente com a ascensão do país na produção de energia nuclear no Oriente Médio - com uma capacidade atual de 79 GWe (Gigawatts Elétricos) -, disputando posição no ranking regional com Israel e Arábia Saudita, os maiores aliados dos EUA (WORLD NUCLEAR ASSOCIATION 2019; Id. 2020a). Assim, o Irã se destaca também pela robustez de sua infraestrutura de pesquisa e desenvolvimento nuclear, com grande número de reatores e instalações de enriquecimento de urânio, conforme mostra a imagem abaixo.

FIGURA 01 - Instalações do Programa Nuclear Iraniano

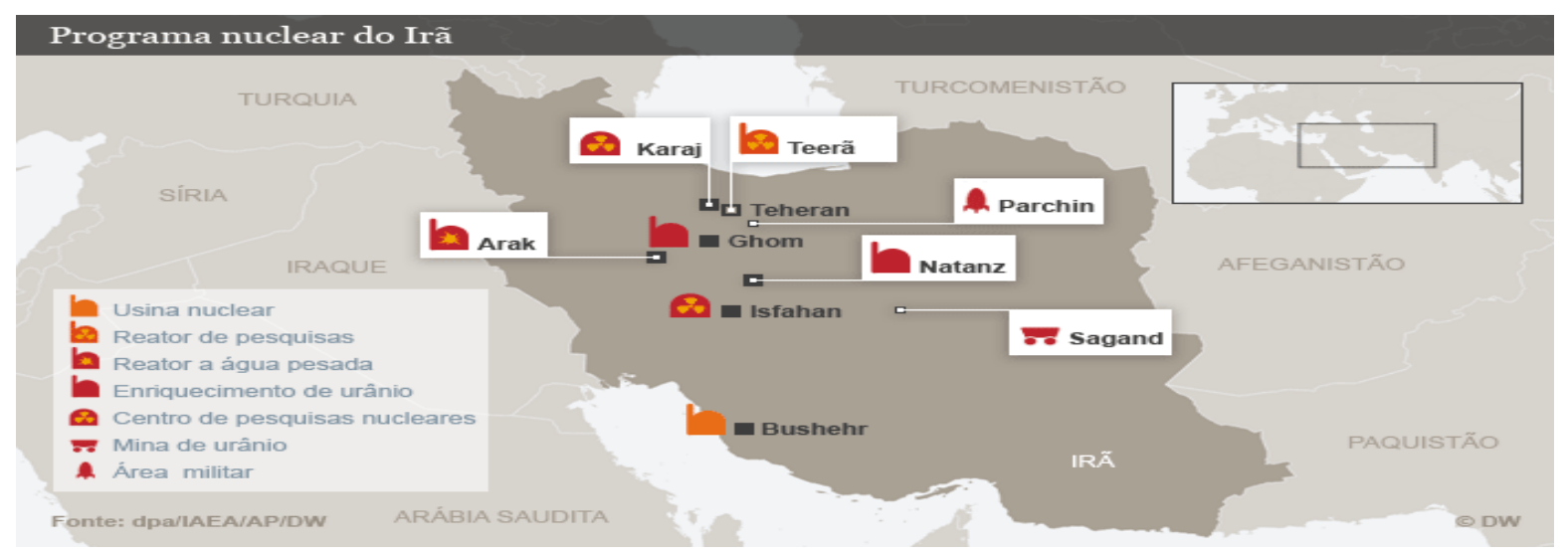

Fonte: DW, 2015

Com o aumento do percentual de enriquecimento para 19,75\% - ultrapassando em muito os 3,67\% permitidos pelo TNP, do qual o Irã é signatário -, o Irã desafia os acordos internacionais sobre o desenvolvimento nuclear, ameaçando chegar a 20\%. Contudo, mesmo com aumento nos percentuais de enriquecimento, o Irã enfatiza que seu desenvolvimento nuclear é para uso civil, estando de acordo com as diretrizes previstas no TNP (TNP, 1970; ARMS CONTROL ASSOCIATION, 2020). Apesar disso, o Irã segue sofrendo retaliações das potências nucleares ocidentais, através de sanções e embargos econômicos, que objetivam dissuadir seu desenvolvimento atômico, pela alegação de que teriam caráter bélico. Tal afirmação se pauta na recusa do governo iraniano em permitir as inspeções da AIEA em suas instalações (WORLD

\footnotetext{
${ }_{18}$ Programa apresentado à Assembleia Geral da ONU, pelo governo estadunidense de Dwight D. Eisenhower, em dezembro de 1953. Tinha como objetivo dar suporte em escala global para a disseminação de tecnologias para o desenvolvimento nuclear para uso civil (GAIETTA, 2015).
} 
NUCLEAR ASSOCIATION, 2020b). O Irã demonstrou sua avançada capacidade de enriquecimento de urânio, capaz de atingir os 90\% necessários à produção de plutônio, matériaprima da bomba atômica, levantando suspeitas sobre as finalidades de seu programa, preocupando o ocidente (BBC, 2010). As hostilidades vêm não somente dos EUA, mas também por parte da União Europeia, que vê a nuclearização do Irã como ameaça aos seus interesses no Oriente Médio (WALTZ, 2012). Além disso, há forte envolvimento também do governo israelense, que frequentemente se manifesta em favor das pressões pela dissuasão nuclear iraniana (PINTO, 2017). Assim, abriu-se margens para o estremecimento das relações Irã-Israel, assim como, das relações com o Ocidente (traduzido nos EUA, na UE e na OTAN), que levaram às principais crises enfrentadas pelo país na história de sua nuclearização.

\subsubsection{AS CRISES NUCLEARES IRANIANAS}

Os principais fatores que levaram o Irã às crises nucleares estão ligados ao confronto político direto com os EUA. Ademais, o descontentamento da comunidade internacional com os descumprimentos do TNP e das Resoluções do Conselho de Segurança das Nações Unidas (CSNU), levaram à aplicação de sanções econômicas que acirraram a disputa. Em particular, destacam-se os esforços dos EUA, no impedimento do desenvolvimento nuclear iraniano, segundo Trump “o Irã nunca terá uma arma nuclear" (TRUMP 2020, tradução dos autores).Tal enfrentamento entre Washington e Teerã é um cenário recente. A primeira crise nuclear do Irã veio a partir da Revolução Islâmica ${ }^{19}$, estremecendo as relações com todo o Ocidente. O aumento do número das instalações nucleares iranianas escalou as tensões até os projetos nucleares de Teerã serem temporariamente suspensos. Na década de 1980, esta primeira crise chega ao ápice quando os EUA incluem o Irã na lista de Estados financiadores do terrorismo, servindo como escusa para a imposição de sanções, que se alastraram ao longo dos anos 90 (ARMS CONTROL ASSOCIATION, 2020).

Em meados de 2002, a "política de opacidade"20 empregada pelo Irã, resultou na segunda crise nuclear. Tal conduta foi vista como uma violação dos acordos de salvaguarda com a AIEA, que previam a obrigatoriedade da declaração formal acerca de toda e qualquer atividade nuclear iniciada por todo e qualquer Estado (LIMA \& FREITAS, 2016). Em 2003, por pressão Ocidental, a AIEA

\footnotetext{
19 Que depôs o líder iraniano alinhado com os ideais ocidentais, Reza Pahlavi.

20 As chamadas "políticas de opacidade" ocorrem quando os Estados adotam uma postura pragmática quanto a um determinado tema, não negando nem afirmando nenhuma informação (LIMA \& FREITAS, 2016). No caso do Irã a manutenção do segredo acerca da construção dos centros nucleares de Natanz (para enriquecimento de urânio) e de Arak (para extração de plutônio).
} 
adota uma resolução que requeria a suspensão das atividades de enriquecimento de Urânio, e reforçava a obrigatoriedade de declaração dos materiais utilizados, e do aceite de inspeções periódicas. O Irã aceitou essa resolução mas não cumpriu com suas disposições, fazendo com que as tensões voltassem a se inflamar em 2004, por Teerã estabelecer um acordo com Moscou para a finalização da construção do reator de Bushehr ${ }^{21}$. Tais ações resultaram no rompimento - por parte da França, Alemanha e Reino Unido - de relações com o Irã e seu encaminhamento para o CSNU em 2006.

Uma terceira fase nas crises nucleares do Irã inicia em 2006, com o acirramento das tensões na ONU, a partir da disputa do $P 5+1^{22}$ no CSNU, que interpela pela suspensão de todas as atividades iranianas de enriquecimento de urânio, implicando em penalidades ao não cumprimento. Desde então, o Irã tem desafiado o CSNU, não somente com a recusa ao cumprimento das disposições, mas também com o aumento do percentual de enriquecimento (PINTO, 2017). Continuando com o comportamento dissidente, em 2009 o Irã anunciou o lançamento de seu primeiro satélite, levantando suspeitas sobre a construção, de uma nova instalação na cidade de Ghom, que foi confirmada e levou a novas negociações entre o P5+1, pressionando o Irã a vender todo o urânio enriquecido, esgotando suas reservas, e limitando suas capacidades de produzir armamentos.

A proposta foi recusada por Teerã, que passou a enriquecer urânio a 20\% em 2010, e triplicou a produção em 2011 na usina de Fordow (ARMS CONTROL ASSOCIATION, 2020). Isso implicou no aumento das sanções transformando-as em "um pacote abrangente e robusto de medidas nas áreas de comércio, serviços financeiros, energia e transporte, além de designações adicionais para a proibição de vistos e congelamento de ativos" (ARMS CONTROL ASSOCIATION 2020, p. 07, tradução nossa). O cenário perdurou durante os anos de 2011/2012, e se agravou com a introdução de novas penalidades por parte de Washington, após Teerã recusar às vistorias da AIEA na base militar de Parchin (DW, 2015). O fim da terceira crise, é observado a partir de 2014, quando as relações entre o Irã e o Ocidente se amenizaram ${ }^{23}$. A manutenção destas relações foi priorizada por Teerã, que decidiu cumprir as requisições do CSNU quanto à redução do enriquecimento de urânio, levando os Estados-membros a renunciarem às sanções impostas.

\footnotetext{
${ }^{21}$ Reator com grande capacidade de geração, que forneceria combustível nuclear para a Rússia.

22 O grupo P5+1 é formado pelos 5 membros permanentes do CSNU (China, França, Estados Unidos, Rússia e Reino Unido) + Alemanha, que se configuram como as grandes potências nucleares reconhecidas no Sistema Internacional orientado pelo regime de não-proliferação.

${ }^{23}$ Com a intensificação da atuação do Estado Islâmico do Iraque e do Levante (ISIS), as tensões se atenuaram por conta dos objetivos compartilhados sobre contenção das atividades terroristas em solo iraquiano, que prejudicavam ambas as agendas securitárias.
} 
Tal feito abriu margem para diálogo e negociações que se fortaleceram em 2015, culminando no Acordo Nuclear entre o Irã e o P5+1 (ARMS CONTROL ASSOCIATION, 2020).

A quarta crise nuclear iraniana se dá desde 2017 até os dias atuais. Seu início vem com a ascensão de Donald Trump à liderança dos EUA, demonstrando preocupação com os mísseis balísticos de Teerã, pressionando a AIEA por inspeções minuciosas ${ }^{24}$. Além disso, Washington decidiu pela não certificação da Lei de Revisão do Acordo Nuclear do Irã, abrindo margem para que as sanções, ora suspensas, recaíssem novamente sobre o Irã. As tensões se agravaram ainda mais quando Trump decidiu sancionar o Corpo da Guarda Revolucionária Islâmica, sob a justificativa de transferência de armas aos rebeldes houthis do Iêmen, que atacaram a Arábia Saudita, violando a Resolução $2231^{25}$ do Acordo. Esta violação resultou no retorno das sanções dos EUA. As tensões atingiram seu ápice em 2018, com a decisão dos EUA de "aplicar pressão financeira sem precedentes ao regime iraniano" (ARMS CONTROL ASSOCIATION 2020, p. 28, tradução nossa), mesmo com as afirmações da AIEA de que o Irã estava cumprindo os dispositivos do Acordo. Neste mesmo ano, as tensões se agravaram com a repentina saída dos EUA do Acordo Nuclear, e escalonaram com a volta do Irã às atividades de enriquecimento, resultando na retirada parcial iraniana do Acordo (CNN 2020, p. 05-06).

Desde então, o Irã expandiu sua produção de urânio enriquecido, ultrapassando os limites do Acordo, e começou a pressionar diplomaticamente o Ocidente por uma reformulação dos termos, visando respaldar o aumento de sua produção. Diante do acirramento das relações com o Ocidente, principalmente após o assassinato do líder da Guarda Revolucionária, Qasem Soleimani em janeiro de 2020 - cuja autoria foi reivindicada pelos EUA -, o governo iraniano anuncia que não mais limitará suas atividades nucleares às restrições do Acordo, a menos que as sanções sejam removidas, e seguem enriquecendo urânio em limites muito acima do permitido, tornando a resolução da crise um cenário ainda distante (CNN, 2020).

\section{COMPARAÇÃO ENTRE IRÃ E COREIA DO NORTE: IMPLICAÇÕES A ESTABILIDADE ESTRATÉGICA}

\subsection{A COREIA DO NORTE NUCLEAR: IMPLICAÇÕES REGIONAIS E GLOBAIS}

\footnotetext{
${ }^{24}$ Ainda que os relatórios demonstrassem que o Irã estava cumprindo as disposições do Acordo, com níveis de enriquecimento de urânio bem abaixo do previsto, não havia confiança, por parte dos EUA, no controle da AIEA.

${ }^{25}$ Referente ao embargo de armas.
} 
O entendimento de estabilidade estratégica surgiu durante a Guerra Fria com o objetivo de compreender as motivações para aquisição, e a real probabilidade do uso de armas nucleares (HUGHES, 2007). A situação na Ásia - caracterizada pelo dilema de segurança - é identificada na Coreia do Norte a partir de seus investimentos em desenvolvimentos nucleares, visando o fortalecimento de sua segurança, e a redução de sua vulnerabilidade frente ao poderio nuclear estadunidense e sul-coreano, que elevam a insegurança regional. Contudo, a modernização das capacidades norte-coreanas faz com que o alcance das armas nucleares, e, consequentemente, de seu poder dissuasório, transborde os limites regionais.

Os autores encontram concordância com o objetivo dos planos estratégicos dos três governos Kim. Nota-se uma reflexão das respostas norte-coreanas às ações estadunidenses na Ásia, passando de uma conotação defensiva em relação às garantias de segurança, ao papel de equalizador securitário entre a Coreia do Sul (ROK) e os Estados Unidos. Hughes (2007) enfatiza que a proliferação nuclear é impulsionada pela combinação de fatores, que giram em torno de capacidades tecnológicas, política econômica doméstica, prestígio e identidade, e segurança nacional. Aliás, esse conjunto de elementos abre margem para indagação a respeito da proliferação: se a Coreia do Norte prosperou através desse caminho, seria possível que mais Estados adotassem o mesmo percurso nuclear?

Em meados da década de 1970 a ROK demonstrou interesse em se tornar uma potência nuclear $^{26}$, contudo, decorrente de pressões de Washington, Seoul optou por não dar continuidade, quadro enfatizado nos governos estadunidenses através de sanções dos anos 1960 até meados dos anos 1990 (HUGHES, 2007; SILER, 1998). Outro ator regional de extrema importância nessa discussão é o Japão ${ }^{27}$, país que hoje apresenta um dos mais avançados programas comerciais de energia nuclear do mundo, contando com cerca de 50 reatores distribuídos em seu território ${ }^{28}$. Atualmente a relação entre a Coreia do Norte e o Japão não é formalmente estabelecida, agravandose cada vez mais devido a contínua atividade missilística norte-coreana, exemplificada no episódio de 2017, onde um míssil da classe Hwasong-12 atravessou o mar do Japão (DW, 2017).

Como apontado por Cho (2016), a Coreia do Norte representa mais do que mera ameaça nuclear, mas uma maneira dos países do Leste Asiático superarem a dependência estadunidense e

\footnotetext{
${ }^{26}$ Os incentivos para que a Coreia do Sul se tornasse um Estado nuclear estariam voltados para três pontos: i) as tendências regionais de proliferação; ii) a segurança nacional; e, iii) obtenção de tecnologias avançadas (SILER, 1998).

${ }^{27}$ Faz-se necessário apontar que visto as intenções japonesas de se tornar uma potência nuclear surgiram por volta da primeira crise nuclear norte-coreana.

${ }^{28}$ No entanto, devido a uma gama de problemáticas internas, existe um crescente movimento popular contrário à continuação do programa nuclear japonês, apesar dele se limitar para uso pacífico (ALDRICH, 2012).
} 
expandirem sua influência no quadro regional. Essa prioridade de longo prazo pode servir às aspirações chinesas à hegemonia regional, um argumento que encontra ressonância na atuação de Pequim nas Six-Party Talks, onde reafirmou sua posição como ator relevante nas dinâmicas securitárias da península coreana e do Leste Asiático ${ }^{29}$ (SHULONG \& XINZHU, 2008).

Há anos os Estados Unidos tentam acabar com o desenvolvimento nuclear e missilístico norte-coreano, mas esse esforço tem sido dificultado devido a imprevisibilidade dos movimentos tomados pelo do governo norte-coreano. No entanto, basta trazer nosso olhar para os pronunciamentos da Coréia do Norte que identificamos seu raciocínio norteador, "se não houvesse a questão nuclear, os Estados Unidos encontrariam falhas em outra questão, e as ameaças políticas e militares não terminariam"30 (JONG-UN 2019, apud KCNA, 2020, \30, tradução nossa). A Coreia do Norte pode ser considerada como uma potência nuclear responsável ao "não usar uma arma nuclear, a menos que sua soberania seja invadida por forças hostis nuclearmente armadas, como já havia declarado, e cumprirá fielmente sua obrigação de não proliferação e lutará pela desnuclearização global”31 (NCNK 2016, p. 11). Assim, apesar da DPRK ter sido enquadrada como parte do "Eixo do Mal”32 e "alvo de ataque nuclear preventivo", os EUA, com seus bloqueios ao desenvolvimento norte-coreano, são os maiores responsáveis pela instabilidade regional.

\subsection{O IRÃ NUCLEAR: RELAÇÕES REGIONAIS E EXTRARREGIONAIS}

De acordo com Waltz (2012), a busca do Irã pelo desenvolvimento nuclear de caráter bélico poderia modificar toda a estrutura securitária do Oriente Médio. Isso porque, dada sua importância enquanto potência nuclear regional, nenhuma decisão adotada por seu governo passaria despercebida, ou sem impactos, para seus vizinhos e para a estrutura securitária da região. Isso ocorre porque o status de potência nuclear vem acompanhado não somente da capacidade de produzir energia atômica, mas também, da capacidade de empregá-la na produção de tecnologias

\footnotetext{
${ }^{29}$ Apesar da busca chinesa pela estabilidade regional ser dificultada pelas provocações norte-coreanas próximas às suas fronteiras, estas não representam um empecilho para a cooperação potencial entre ambos, haja vista que, ao encorajar uma maior abertura de Pyongyang, as tensões irão diminuir relativamente (CHO, 2016).

30 Tradução nossa do original: "If there were not the nuclear issue, the U.S. would find fault with us under other issues, and the U.S. military and political threats would not end" (KCNA, 2020, \$ 30).

31 Tradução nossa do original: "will not use a nuclear weapon unless its sovereignty is encroached upon by any aggressive hostile forces with nukes, as it had already declared, and it will faithfully fulfill its obligation for nonproliferation and strive for the global denuclearization" (NCNK 2016, p. 11).

${ }^{32}$ Em 2002 o Presidente estadunidense George W. Bush utilizou a expressão "Eixo do Mal” direcionado aos países que eram considerados inimigos ou hostis aos Estados Unidos, acusando-os de terrorismo. Presentes nesta lista encontrava-se o Irã, a Coreia do Norte e o Iraque.
} 
de uso civil, e principalmente militar, dando à Teerã enorme capacidade de defesa e até mesmo de ataque em um possível escalonamento de conflito com Israel, seu principal oponente regional.

O número de instalações nucleares do Irã choca a comunidade internacional pelo deste se configurar como uma das maiores potências militares da região, empregando uma abordagem híbrida das práticas de guerra, mesclando elementos convencionais (baseados na dissuasão e na capacidade de retaliação) e não-convencionais (baseados nas operações de guerra irregular, como a Força Quds ${ }^{33}$, em parceria com atores não-estatais), em confrontação com as forças de Arábia Saudita e Israel (U.S. DEPARTMENT OF DEFENSE, 2019). De todos os elementos que compõem a força militar iraniana, a confiança em um extenso programa de mísseis balísticos, é o que mais preocupa o Ocidente com relação ao desenvolvimento de um sólido programa nuclear, pois:

Os mísseis balísticos do Irã constituem um componente primário de seu impedimento estratégico. Na falta de uma força aérea moderna, o Irã adotou mísseis balísticos como uma capacidade de ataque de longo alcance para dissuadir seus adversários de atacarem o Irã. O Irã também possui a maior força de misseis do Oriente Médio, com inventário substancial de mísseis balísticos de curto alcance e mísseis balísticos de médio alcance que podem atingir alvos em toda a região a até 2.000 quilômetros de distância (U.S. DEPARTMENT OF DEFENSE 2019, \09, grifo nosso).

Em decorrência do largo poder militar iraniano, os EUA passaram a investir em uma presença cada vez maior no Oriente Médio, a fim de implementar sistemas Patriot ${ }^{34}$ de defesa aérea antimíssil buscando frear possíveis ataques aos seus aliados do Golfo. Além disso, nota-se um aumento exponencial não somente da militarização no Complexo Regional de Segurança do Oriente Médio, mas também na interferência externa nos processos de tomada de decisão regionais pelo Ocidente. Assim, vemos o agravamento das instabilidades já existentes, e a eclosão de novos elementos de tensão entre os Estados. Isso ocorre tanto pelo maior contingente de armamentos bélicos dentro de um território, como também pela multiplicação de atores extrarregionais nesta dinâmica regional, complexificando a resolução dos conflitos e a redução das instabilidades.

Conforme supracitado, Waltz (2012) aponta que a crise nuclear iraniana poderia ter três desfechos diferentes. No primeiro cenário, a diplomacia das potências ocidentais orquestraria inúmeros esforços, na implementação de embargos, sanções e resoluções via CSNU, pela dissuasão

\footnotetext{
33 Operação não-convencional, liderada pelo General Qasem Soleimani, com o objetivo de desmantelar as células do ISIS operantes no Irã e no Iraque. Contou com a união de grupos paramilitares como os militantes do Hezbollah, os rebeldes Houthis do Iêmen, além de alguns grupos de xiitas do Iraque e do Bahrein, a Jihad Islâmica palestina e militantes do Talibã (Ibid. \11).

${ }^{34}$ O MIM-104 Patriot é o sistema de defesa antiaérea criado pela coalizão das empresas Raytheon, Hughes e RCA dos Estados Unidos. Estão em operação atualmente em países como EUA, Alemanha, Japão, Emirados Árabes Unidos, Taiwan, Holanda, Coreia do Sul, Arábia Saudita, Espanha, Grécia, Israel, Bahrein, Egito, Jordânia, Kuwait e Qatar.
} 
das atividades nucleares do Irã. Trata-se de uma hipótese improvável, pois tais estratégias apresentam um histórico pouco efetivo no âmbito internacional. Ademais, segundo o exemplo norte-coreano, as punições poderiam não somente falhar, como causar o efeito contrário, levando ao abandono do próprio TNP. Ademais, no rol de preocupações dos Estados, há uma assimetria que coloca as questões securitárias à frente das relações diplomáticas e econômicas, desta forma, se o governo iraniano decidir que sua segurança, defesa e sobrevivência dependem do desenvolvimento nuclear, as sanções da comunidade internacional terão pouco êxito em dissuadilo (WALTZ, 2012).

No segundo cenário, em uma conjuntura de maior cooperação por parte do Irã, não haveria tanto afinco na produção de armas com vistas a um ataque nuclear, mas haveria maior empenho na construção de um programa de defesa nuclear com alto nível tecnológico e capacidade de produção atômica, mas sem de fato construir uma bomba (estratégia que estaria em conformidade com as disposições do TNP, e poderia galgar certa margem de manobra com os países ocidentais - estratégia adotada antes do escalonamento de tensões em 2017). O autor mostra que essa estratégia poderia pacificar as relações com o Ocidente, sem implicar na extinção do programa nuclear iraniano.

Contudo, isso ainda perturbaria a ordem regional, aumentando os programas militares de defesa e ataque, devido ao alto índice de militarização do CRS do Oriente Médio. Desta forma, em um cenário onde se agravassem as disputas entre os agentes regionais, desafiando a integridade das alianças formadas com o Ocidente, poderia haver o escalonamento de um conflito armado de grandes proporções, dados os contingentes de tropas e aparatos militares disponíveis por cada coalizão, conforme o quadro abaixo:

QUADRO 02 - Cenários para invasão do Irã (capacidades militares das alianças e coalizões)

\begin{tabular}{|c|c|c|c|c|c|c|c|}
\hline & $\begin{array}{c}\text { TANQUES } \\
\text { (MIL) }\end{array}$ & CACDAS & BOMBARDEIROS & $\begin{array}{l}\text { APTOS AO } \\
\text { SERVICOO } \\
\text { MILITAR } \\
\text { (MIL) }\end{array}$ & subs & $\begin{array}{l}\text { SUB } \\
\text { NUC. }\end{array}$ & $\begin{array}{l}\text { PORTA } \\
\text { AVIÓES }\end{array}$ \\
\hline $\begin{array}{c}\text { ÁSIA (IRÃ, CHINA, } \\
\text { RUSSIA, TURQUIAE } \\
\text { EGITO) }\end{array}$ & 35 & 2.661 & 3.594 & 775.886 & 182 & 17 & $z$ \\
\hline $\begin{array}{c}\text { OCIDENTE (EUA, } \\
\text { ISRAEL, A. SAUD } \\
\text { FRANC,A, UK, } \\
\text { ALEMANHA E ITALIA) }\end{array}$ & 16 & 3.451 & 4.079 & 236.955 & 112 & 22 & 26 \\
\hline EUA E ISRAEL & 13 & 2.551 & 3.028 & 123.025 & 81 & 14 & 19 \\
\hline
\end{tabular}

Fonte: PINTO (2017) 
O terceiro cenário aponta para a continuidade das atividades nucleares do Irã, até o ponto do desenvolvimento e teste público de sua primeira arma nuclear. Este é o cenário considerado como “inaceitável” pelo Ocidente, que considera um Irã nuclearizado como uma "ameaça existencial". A linguagem empregada pelo P5+1 para se referir ao Irã e a outras potências nucleares em ascensão, como a Coreia do Norte, é vista por Waltz como típica no tratamento com quaisquer países fora do Clube Nuclear, que pressiona os demais países a reduzirem seus avanços nucleares, mas seguem desenvolvendo seus próprios programas. $\mathrm{O}$ autor reconhece ainda que o desenvolvimento de armas nucleares reduz a grande assimetria no poderio militar existente entre centro, semiperiferias e periferias, culminando muito mais na garantia da segurança e da estabilidade, do que na eclosão de conflitos.

Waltz afirma ainda que o fator que perpetua a instabilidade no CRS do Oriente Médio é muito mais o monopólio regional sobre o armamento nuclear que Israel detém, do que as aspirações iranianas na aquisição de um arsenal limitado. Com isso, sugere que a instabilidade regional não será recuperada a menos que a assimetria de poder e capacidades militares seja contrabalançada pelo Irã, através da aquisição deste tipo de armamento, recorrendo ao conhecido ambiente da destruição mútua assegurada, no qual nenhum Estado arrisca ataques por conhecer o poder de retaliação de seu rival. Assim, ao trazer a comparação com o Estado norte-coreano, é possível observar que, ao longo da história, a emergência de capacidades nucleares vem acompanhada do aumento da estabilidade regional. Destarte, considera-se que, muito mais do que uma potência nuclear em ascensão, o Irã se configura também como ator no papel de estabilização do CRS do Oriente Médio, ao passo que se coloca como contraparte às políticas hostis de Israel, e à influência extrarregional, que tornam este eixo geográfico ainda mais instável e de difícil resolução.

\section{CONSIDERAÇÕES FINAIS}

O presente artigo teve como objetivo traçar diferenças e semelhanças no desenvolvimento dos programas atômicos de duas potências nucleares emergentes, que situam-se na intersecção de interesses das grandes potências presentes tanto no Leste Asiático, quanto no Oriente Médio e que acabam desencadeando uma série de dilemas securitários regionais. Partindo-se da premissa de que o caráter dissuasório existente nos armamentos nucleares configura-se como uma presença estabilizante em cenários de disparidades militares regionais, buscou-se explorar como tal variável interveniente poderia afetar as políticas regionais do Oriente Médio, com base no desenvolvimento 
apresentado pelo Estado norte-coreano. De forma preliminar, de acordo com os cenários projetados, a presente pesquisa confirma sua hipótese, em conformidade com o entendimento de Waltz (2012): “o poder implora para ser equilibrado” (WALTZ 2012, p. 3, tradução nossa)

Como apresentado anteriormente, a Teoria da Dissuasão não configura-se apenas como um marco teórico-conceitual, consistindo também numa diretriz de política externa, e um elemento constitutivo do entendimento sobre a defesa do SI moderno. Os autores reconhecem que a defesa da aquisição de um armamento, com a potencialidade destrutiva singular de uma arma nuclear, por parte de um país como o Irã não pode ser levianamente apresentada. É necessária a apresentação de dados empíricos que corroborem com o argumento de que essa aquisição seria benéfica tanto para o Estado iraniano, quanto para toda a estrutura regional.

Acreditamos que o êxito norte-coreano seja exemplar do potencial emancipatório do armamento atômico, respaldada em sua demonstrada capacidade de desafiar e afetar as intenções imperialistas até mesmo da maior potência militar do mundo. Como brevemente exposto, a assimetria característica da segunda era nuclear que conspira a favor dos EUA e cria novos riscos à estabilidade estratégica ao tornar outros Estados no Sistema Internacional menos dispostos a reduzir sua dependência de seu arsenal nuclear nacional, como é o caso da DPRK e do Irã.

Portanto, cautelosamente, com base em um suporte teórico apropriado, trazemos um exemplo histórico semelhante à situação iraniana. Contudo, reconhece-se tanto o caráter exploratório da presente pesquisa, quanto o fato de que a densidade e a complexidade do tema tornam impossível a plena confirmação da hipótese levantada por meio do presente artigo. Abrese margem para agendas de pesquisas futuras que complementem e corroborem a hipótese apresentada, de que a melhor saída para a estabilidade regional no Oriente Médio seja a aquisição de armamento nuclear por parte do governo iraniano.

\section{REFERÊNCIAS}

AKHTAR, S.; KHAN, Z. 2014. Understanding the Nuclear Aspirations and Behaviour of North Korea and Iran. Strategic Analysis, [s.l], vol. 38, n. 5, p. 617-633, [s.d].

ALDRICH, D. 2012. Post-Crisis Japanese Nuclear Policy: From Top-Down Directives to BottomUp Activism. East-West Center, [s.l], n. 103, p. 12, [s.d].

ARMS CONTROL ASSOCIATION. 2020. Timeline of Nuclear Diplomacy with Iran. Disponível em: $<$ https://www.armscontrol.org/factsheets/Timeline-of-Nuclear-Diplomacy-With-Iran $>$. Acesso em 26 jun. 2020. 
ATOMIC HERITAGE FOUNDATION. 2018. Chinese Nuclear Program. Disponível em:

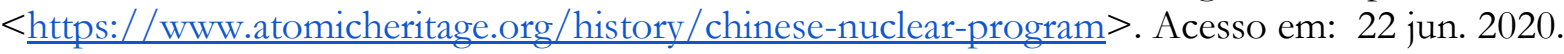

BBC. 2010. Entenda a polêmica envolvendo o programa nuclear do Irã. Disponível em: $<$ https://www.bbc.com/portuguese/noticias/2009/11/091121 ira qanda nuclear np $>$. Acesso em: 24 jun. 2020.

BBC. 2019. Yongbyon: The heart of North Korea's nuclear programme. Disponível em: <https://www.bbc.com/news/world-asia-47397699>. Acesso em: 22 jun. 2020.

BBC News Brasil. 2020. Qual o tamanho do poderia militar do Irã?. Disponível em: <https://www.bbc.com/portuguese/internacional-50988198>. Acesso em: 24 jun. 2020.

BUZAN, B.; WAEVER, O. 2003. Regions and powers: The structure of international security. 1 ed. New York: Cambridge University Press.

CBS. 2017. A timeline of North Korea's nuclear tests. Disponível em: $<$ https://www.cbsnews.com/news/north-koreas-nuclear-tests-timeline/>. Acesso em: 22 jun. 2020.

CHO, Il H. 2016. Global Rogues and Regional Orders: The Multidimensional Challenge of North Korea and Iran. New York: Oxford University Press.

CLAUSEWITZ, C. 2007. On war. HOUSER, Beatrice (ed.). 1st. ed. [S. l.: s. n.].

CLEMENS, W. 2010. North Korea's Quest for Nuclear Weapons: New Historical Evidence. Journal of East Asian Studies, vol. 10, n. 1, p. 127-154.

CNN. 2020. Iran's nuclear capabilities fast facts. Disponível em: < https://edition.cnn.com/2013/11/07/world/meast/irans-nuclear-capabilities-fast-

facts/index.html >. Acesso em: 26 jun. 2020.

DW $=$ Deutsche Welle. 2015. Cronologia da crise do programa nuclear iraniano. Disponível em: $<$ https://www.dw.com/pt-br/cronologia-da-crise-do-programa-nuclear-iraniano/a-18293677>.

Acesso em: 25 jun. 2020.

DW. 2017. Por que o Japão não interceptou o missil norte-coreano?. Disponível em: $<$ https://www.dw.com/pt-br/por-que-o-jap $\%$ C3\%A3o-n $\%$ C3\%A3o-interceptou-Om\%C3\%ADssil-norte-coreano/a-40301861>. Acesso em: 29 jun. 2020.

FRENCH, P. 2007. North Korea: The Paranoid Peninsula - A Modern History. London: Zed Books.

GAIETTA, M. 2015. The trajectory of Iran's Nuclear Program. New York: Palgrave MacMillan.

HERZ, J. 1950. Idealist internationalism and the security dilemma, In: World Politics, vol.2, n.2, p.157-180.

HUGHES, C. 2007. North Korea's Nuclear Weapons: Implications for the Nuclear Ambitions of Japan, South Korea, and Taiwan. Asia Policy, n. 3, p. 75-104.

JARVIS, R. 2009. Deterrence, Rogue States, and the U.S. Policy. In: PAUL, V.T.; MORGAN, Patrick M.; WIRTZ, James J. (org.). Complex Deterrence: Strategy in the Global Age. [S. l.]: University of Chicago Press. cap. 6, p. 133-157. 
KCNA. 2020. Report on 5th Plenary Meeting of 7th C.C., WPK. Disponível em:

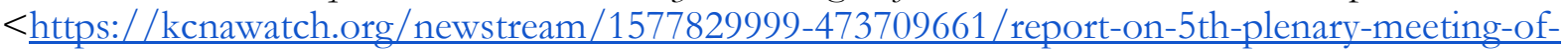
7th-c-c-wpk/>. Acesso em: 29 jun. 2020.

KHAN, S. 2010. Iran and Nuclear Weapons: Protracted Conflict and Proliferation. New York: Routledge.

KNOPF, Jeffrey W. 2009. Three Items in One: Deterrence as Concept, Research Program, and Political Issue. In: PAUL, V.T.; MORGAN, Patrick M.; WIRTZ, James J. (org.). Complex Deterrence: Strategy in the Global Age. [S. l.]: University of Chicago Press. cap. 2, p. 31-57.

KREPON, M. 2003. The Stability-Instability Paradox, Misperception, and Escalation Control in South Asia. The Henry L. Stimson Center, [s. l.], p. 1-24. Disponível em: $<$ https://theasiadialogue.com/wp-content/uploads/2017/10/stability-instability-paradox-southasia.pdf $>$. Acesso em: 15 jun. 2020.

LIMA, M.; FREITAS, M. 2016. Programa Nuclear do irã e panorama internacional. In: Revista Jurídica, v. 3, n. 44, Curitiba/PR, p. 355-380.

LOWTHER, A; DODGE, M. 2017. The Threat Environment Demands Nuclear Weapons Modernization. Air \& Space Power Journal, vol. 31, no. 3, p. 4+.

MCEACHERN, P.; MCEACHERN, J. 2018. North Korea, Iran, and the Challenge to International Order: A Comparative Perspective. New York: Routledge.

MORGADE, A. 2020. EUA X Irã: o que originou a rivalidade de décadas entre os dois países. In: BBC News Brasil, [online]. Disponível em: < https://www.bbc.com/portuguese/internacional50983943 >. Acesso em: 25 jun. 2020.

NCNK. 2016. Documents from the 7th Workers' Party Congress. Disponivel em: $<$ https://www.ncnk.org/sites/default/files/content/resources/publications/KJU Speeches 7th Congress.pdf $>$. Acesso em: 27 jun. 2020.

NCNK. 2017. Kim Jong Un's 2017 New Year's Address. Disponível em:

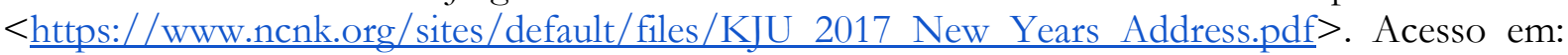
27 jun. 2020.

NIKKEI ASIAN REVIEW. 2019. A satellite view of North Korea's nuclear sites. Disponível em: $<$ https://asia.nikkei.com/static/vdata/north-korea-nuclear/newsgraphics/north-koreanuclear/index.html >. Acesso em: 28 jun. 2020.

NTI $=$ Nuclear Threat Initiative. 2020. The CNS North Korea Missile Test Database. Disponível em: $<$ https://www.nti.org/analysis/articles/cns-north-korea-missile-test-database/>. Acesso em: 26 jun. 2020.

NTI. 2018. North Korea Nuclear. Disponível em: < https://www.nti.org/learn/countries/northkorea/nuclear/>. Acesso em: 25 jun. 2020.

PAUL, V.T. 2009. Complex Deterrence: An Introduction. In: PAUL, V.T.; MORGAN, Patrick M.; WIRTZ, James J. (org.). Complex Deterrence: Strategy in the Global Age. [S. l.]: University of Chicago Press, cap. 1, p. 1-27.

PAYNE, K. 2003. The Fallacies of Cold War Deterrence and a New Direction. Comparative Strategy, [s. l.], $\quad$ v. $22, \quad$ ed. $5, \quad$ p. 411-428. Disponível em: 
< https://www.tandfonline.com/doi/abs/10.1080/01495930390261431>. Acesso em: 15 jun. 2020 .

PETERSON, S. 2011. Imminent Iran Nuclear Threat? A timeline of warnings since 1979. In: Christian Science Monitor, [online]. Disponível em: < https://www.csmonitor.com/World/MiddleEast/2011/1108/Imminent-Iran-nuclear-threat-A-timeline-of-warnings-since-1979/Earliestwarnings-1979-84>. Acesso em: 25 jun.2020.

PINTO, M.A.C. 2017. A crise nuclear no Irã e os riscos de uma solução militar. In: Brasil Debate, [online]. Disponível em: <http://brasildebate.com.br/a-crise-nuclear-no-ira-em-tempos-detrump/>. Acesso em: 25 jun. 2020.

REUTERS. 2014. Nuclear North Korea. Disponível em: $<$ http:// fingfx.thomsonreuters.com/gfx/rngs/1/466/597/index.html\#section-reuters-section1>. Acesso em: 25 jun. 2020.

ROMASHKINA, N. 2007. North Korea and Iran's Nuclear Programs as Instability Factors in the New System of International Relations. George C. Marshall European Center for Security Studies, n. 13, $49 \mathrm{p}$.

SAUER, T. 2006. The Nuclear Nonproliferation Regime in Crisis. Peace Review: A Journal of Social Justice, vol. 18, n. 3, p. 333-340.

SILER, M. 1998. U.S. Nuclear Nonproliferation Policy in the Northeast Asian Region During the Cold War: the South Korea Case. East Asian Studies, vol. 16, p. 41-86.

STACK, L. 2018. Korean War, a Forgotten' Conflict That Shaped the Modern World. NYTIMES. Disponível em: <https://www.nytimes.com/2018/01/01/world/asia/korean-war-history.html>. Acesso em: 20 jun. 2020.

TNP $=$ Tratado de Não-Proliferação Nuclear (Non-Proliferation Treaty) (1970). 2010. In: U.S. Delegation to the 2010 Nuclear Nonproliferation Treaty Review Conference. Disponível em: < https://20092017.state.gov/documents/organization/141503.pdf>. Acesso em 24 jun. 2020.

TRUMP, Donald J. 2020. "Iran will never have a nuclear weapon!". 06 jan. 2020, 11:48 am. Tweet. Disponível em: < https://twitter.com/realDonaldTrump/status/1214197038063243266?s=20 >. Acesso em: 25 jun. 2020.

$\mathrm{UN}=$ United Nations. 1992a. Joint Declaration of the Denuclearization of the Korean Peninsula. Disponivel em:

< https://peacemaker.un.org/sites/peacemaker.un.org/files/KR\%20KP 920120 JointDeclaratio nDenuclearizationKoreanPeninsula.pdf $>$. Acesso em: 24 jun. 2020.

UN. 1992b. Agreement on Reconciliation, Non-aggression and Exchanges and Cooperation between the South and the North. Disponivel em: < https://peacemaker.un.org/sites/peacemaker.un.org/files/KR\%20KP 911213 Agreement $\% 2$ 0on $\% 20$ reconciliation $\% 20$ non $\% 20$ aggression $\% 20$ and $\% 20$ exchangespdf.pdf $>$. Acesso em: 24 jun. 2020.

UN. 2006. Resolution 1718.2 Disponível em: <https://www.securitycouncilreport.org/atf/cf/\%7B65BFCF9B-6D27-4E9C-8CD3CF6E4FF96FF9\%7D/NKorea\%20SRES\%201718.pdf>. Acesso em: 27 jun. 2020. 
UN. 2009. Resolution 1874. Disponível em: <http://unscr.com/en/resolutions/doc/1874> Acesso em: 28 jun. 2020.

U.S. DEPARTMENT OF DEFENSE. 2019. Iran Military Power Report Statement. Disponível em: $<$ https://www.defense.gov/Newsroom/Releases/Release/Article/2021009/iran-military-powerreport-statement/>. Acesso em 25 jun. 2020.

WALTZ, K. 1990. Nuclear Myths and Political Realities. The American Political Science Review, [s. l.], v. 84, ed. 3, p. 731-745. Disponível em: < https://www.jstor.org/stable/1962764? seq=1 >. Acesso em: 20 jun. 2020.

WALTZ, K. 2012. Why Iran Should Get the Bomb: Nuclear Balancing Would Mean Stability. Foreign Affairs. Disponível em: < https://www.foreignaffairs.com/articles/iran/2012-06-15/why-iranshould-get-bomb $>$. Acesso em: 02 mar. 2020.

WORLD NUCLEAR ASSOCIATION. 2020a. Emerging Nuclear Energy Countries. Disponível em: $<$ https://www.world-nuclear.org/information-library/country-profiles/others/emergingnuclear-energy-countries.aspx $>.24$ jun. 2020.

WORLD NUCLEAR ASSOCIATION. 2020b. Nuclear Power in Iran. Disponível em: $<$ https://www.world-nuclear.org/information-library/country-profiles/countries-g-n/iran.aspx >. Acesso em 24 jun. 2020.

WORLD NUCLEAR ASSOCIATION. 2019. Nuclear Power in Saudi Arabia. Disponível em: $<\underline{\text { https://www.world-nuclear.org/information-library/country-profiles/countries-O-s/saudi- }}$ arabia.aspx >. Acesso em 24 jun. 2020. 